\title{
Editorial
}

\section{Cognitive Robotics}

\author{
János Botzheim (D)
}

check for

updates

Citation: Botzheim, J. Cognitive Robotics. Electronics 2021, 10, 1510. https://doi.org/10.3390/electronics 10131510

Received: 15 June 2021

Accepted: 18 June 2021

Published: 22 June 2021

Publisher's Note: MDPI stays neutral with regard to jurisdictional claims in published maps and institutional affiliations.

Copyright: (C) 2021 by the author Licensee MDPI, Basel, Switzerland. This article is an open access article distributed under the terms and conditions of the Creative Commons Attribution (CC BY) license (https:// creativecommons.org/licenses/by/ $4.0 /)$.
Department of Mechatronics, Optics and Mechanical Engineering Informatics, Faculty of Mechanical Engineering, Budapest University of Technology and Economics, 1111 Budapest, Hungary; botzheim@mogi.bme.hu

Recently, various types of intelligent robots have been developed for the society of the next generation. The evolution of robots and also robotics has already taken a huge step since the first appearance of the word "Robot" in Karel Čapek's science-fiction play Rossum Universal Robots at the beginning of the 20th century. Industrial robotics has evolved a lot since the first introduction of Robert C. Devol's Unimate to nowadays [1]. Until now, robots only worked behind walls, in factories, in places where there was not so much interaction with them, but nowadays, they are becoming an integral part of our lives, and that is why the efficiency of human-robot interaction is becoming more and more important [2]. Besides industrial environments, robots should also perform tasks in real environments such as houses, commercial facilities, and public facilities. Robots are used nowadays in the military, hospitals, transportation, nursing homes and so on. They play an increasing role in elderly care as well [3]. Robots make our lives more and more convenient in many aspects. The growing need to automate daily tasks combined with new robot technologies drives the development of human-friendly robots, i.e., safe and dependable machines, operating in close vicinity to humans or directly interacting with persons in a wide range of domains. The technology shift from classical industrial robots that are safely kept away from humans in cages to robots used in close collaboration with humans requires major technological challenges that need to be overcome. Robots should perform verbal and non-verbal interaction with human [4] and emotions may also play an essential role in the interaction [5].

Computational intelligence [6] is very important to provide human-friendly services by robots. Computational intelligence models and algorithms may provide acceptably sub-optimal, usually approximate solutions for complex problems, while keeping the computational complexity (both in the senses of space and time) at a tractable, usually low degree polynomial level. They aim to imitate human reasoning and learning processes and realize nature-inspired optimization techniques as well. A robot should have human-like intelligence and cognitive capabilities to co-exist with people. Facial recognition, gesture recognition, emotion expression, behavior generation, decision making, reasoning, learning are vital components an intelligent robot should realize. The study on the intelligence, cognition, and self of robots has a long history. The concepts of adaptation, learning, and cognitive development should be introduced more intensively in the next-generation robotics from the theoretical point of view. Fuzzy systems, neural networks, and evolutionary computation play an important role in realizing the cognitive development of robots from a methodological point of view. Furthermore, the synthesis of information technology, network technology, and robot technology may bring the brand-new emerging intelligence to robots from a technical point of view.

This Special Issue focuses on the intelligence of robots emerging from the adaptation, learning, and cognitive development through the interaction with people and dynamic environments from the conceptual, theoretical, methodological, and technical points of view.

Funding: This research received no external funding.

Conflicts of Interest: The author declares no conflict of interest. 


\section{References}

1. Ballard, L.A.; Šabanović, S.; Kaur, J.; Milojević, S. George Charles Devol, Jr. [History]. IEEE Robot. Autom. Mag. 2012, 19, 114-119. [CrossRef]

2. Goodrich, M.A.; Schultz, A.C. Human-Robot Interaction: A Survey. Found. Trends Hum. Comput. Interact. 2007, 1, 203-275. [CrossRef]

3. Robinson, H.; MacDonald, B.; Broadbent, E. The role of healthcare robots for older people at home: A review. Int. J. Soc. Robot. 2014, 6, 575-591. [CrossRef]

4. Mavridis, N. A review of verbal and non-verbal human-robot interactive communication. Robot. Auton. Syst. 2015, 63, 22-35. [CrossRef]

5. Szabóová, M.; Sarnovský, M.; Maslej Krešňáková, V.; Machová, K. Emotion Analysis in Human-Robot Interaction. Electronics 2020, 9, 1761. [CrossRef]

6. Fogel, D.B.; Liu, D.; Keller, J.M. Fundamentals of Computational Intelligence: Neural Networks, Fuzzy Systems, and Evolutionary Computation; IEEE Press: Piscataway, NJ, USA, 2016. 